\title{
Management of Hypertension Using Olmesartan Alone or in Combination
}

\author{
Xiaoshen Zhang $\cdot$ Han Zhang $\cdot$ Yuxia Ma $\cdot$ Wenliang Che $\cdot$ \\ Michael R. Hamblin (D)
}

Received: January 17, 2017 / Published online: March 3, 2017

(c) The Author(s) 2017. This article is published with open access at Springerlink.com

\begin{abstract}
Hypertension is one of the most significant and consistent risk factors for many cardiovascular diseases. The global prevalence of hypertension has dramatically increased over recent years. Life-style and genetic factors are generally considered to be primarily responsible for the
\end{abstract}

Enhanced content To view enhanced content for this article go to http://www.medengine.com/Redeem/ E097F0602FD64106.

X. Zhang $\cdot$ H. Zhang $\cdot$ W. Che

Department of Cardiology, Shanghai Tenth Hospital of Tongji University, Shanghai 200072, China

\section{Zhang}

Tongji University Cancer Institute, Tongji

University School of Medicine, Shanghai 200092,

China

X. Zhang - M. R. Hamblin ( ()

Wellman Center for Photomedicine, Massachusetts

General Hospital, Boston, MA 02114, USA

e-mail: hamblin@helix.mgh.harvard.edu

\section{Y. Ma}

Department of Internal Medicine, Cangzhou

Central Hospital, Cangzhou, China

\section{R. Hamblin}

Department of Dermatology, Harvard Medical

School, Boston, MA 02115, USA

M. R. Hamblin

Harvard-MIT Division of Health Sciences and

Technology, Cambridge, MA 02139, USA incidence of hypertension. Concerning the high morbidity rate, setting up an updated standard for hypertensive patients becomes indispensable. According to the widely accepted standard treatments for hypertension, these four basic principles should be taken into account: low dosage; medication should provide long term-control; combination therapies are becoming common; personalized treatments are a newer approach. In most patients with hypertension, adequate control of BP can be achieved with combined therapy. Therefore, antihypertensive agents with complementary mechanisms are now recommended. In this review, we focus on the pharmacology, antihypertensive efficacy, and adverse events (AEs) of olmesartan medoxomil, either alone or in combination with other antihypertensive medications. In conclusion, olmesartan medoxomil, is an angiotensin II receptor blocker with an excellent efficacy in the reduction and stabilization of blood pressure. When combined with calcium channel blockers (CCBs) and diuretics, olmesartan medoxomil has a better effect on controlling $\mathrm{BP}$ and reducing AEs in patients.

Keywords: Angiotensin II receptor blockers; Blood pressure control; Combination drug treatment; Hypertension; Olmesartan medoxomil 


\section{INTRODUCTION}

Elevated blood pressure (BP) or hypertension has become one of the biggest single contributors to the global burden of disease and global mortality [1]. Hypertension causes the premature death of over 9.4 million people worldwide every year according to a 23 -year-long systemic analysis [2], and was responsible for approximately 10.4 million deaths in 2013 [3]. At the start of this century, it was estimated that nearly 972 million people worldwide had hypertension, and it was predicted that the prevalence would increase to over 1.56 billion by 2025 [4]. The prevalence of hypertension among people aged 35-64 years in the US population is about $30 \%$ [5] and about 44\% in European countries [6]. Moreover, hypertension continues to be undertreated $[7,8]$.

The chief aim of the diagnosis and treatment of hypertension is to reduce death and morbidity from cardiovascular disease [9] (see Fig. 1). With optimum control of BP, it is possible to prevent damage to many organ systems, and the treatment of underlying vascular diseases is also an important management objective [10]. Achieving BP goals is a persistent challenge for hypertensive patients with low to moderate risk, and reaching the figure of $130 / 80 \mathrm{mmHg}$ is a goal for high-risk patients, such as those with diabetes, cardiovascular disease, or renal disease [11]. The guidelines for the management of hypertension in the United States, Europe, and Japan recommend considering a combination of two drugs at the beginning of treatment in high-risk patients or those with grades 2-3 hypertension [12-14]. Therefore, in clinical practice, two or more drugs with different mechanisms of action are often chosen, and are considered to have a better prospect to achieve satisfactory BP control. Olmesartan is classified as an angiotensin receptor blocker (ARB).

\section{METHODS}

The literature searches were conducted in March to April 2016 using PubMed and Excerpta Medica Database (EMBASE) together with the Web of Science database. We selected influential randomized controlled trials in the field of hypertension research. In brief, we used keywords such as olmesartan medoxomil monotherapy, or versus placebo or antihypertensive mono or combination therapy (trial duration at least 2 months). We included trials with drugs in adults, men, and non-pregnant women, with uncomplicated primary hypertension. Trials that had oral antihypertensive treatment with other angiotensin II receptor blockers (ARBs), thiazide and thiazide-like diuretics, calcium-channel blockers and angiotensin-converting enzyme inhibitors (ACEI), as comparators, were eligible for inclusion. The contents of this article are based on previously published studies and do not involve any new studies of human or animal subjects performed by any of the authors.

\section{Discovery and Development of Angiotensin Receptor Blockers}

In 1898, the physiologist Robert Tigerstedt and his student, Per Bergman, working at the Karolinska Institute in Stockholm, Sweden, injected rabbits with different kinds of kidney extracts, and found some caused a rise in blood pressure [15]. They named the active principle "renin", and suggested it was a protein due to its water-soluble, non-dialyzable, and heat-labile properties. However, this remarkable discovery remained largely unexplored for almost 40 years. In the 1930s, Harry Goldblatt conducted experiments in which he constricted the blood flow to the kidneys in dogs, and found that ischemia caused the kidneys to secrete a substance that caused vasoconstriction [16]. Although initially it was thought that this substance was the same as the renin discovered by Tigerstedt, attempts to purify it produced less hypertensive activity, rather than the higher activity that was expected. In 1939, renin itself was found not to cause the rise in blood pressure, but rather was an enzyme that catalyzed the formation of another substance that actually was responsible, initially named "angiotonin" and "hypertensin", and then the compromise name "angiotensin" was agreed. It 


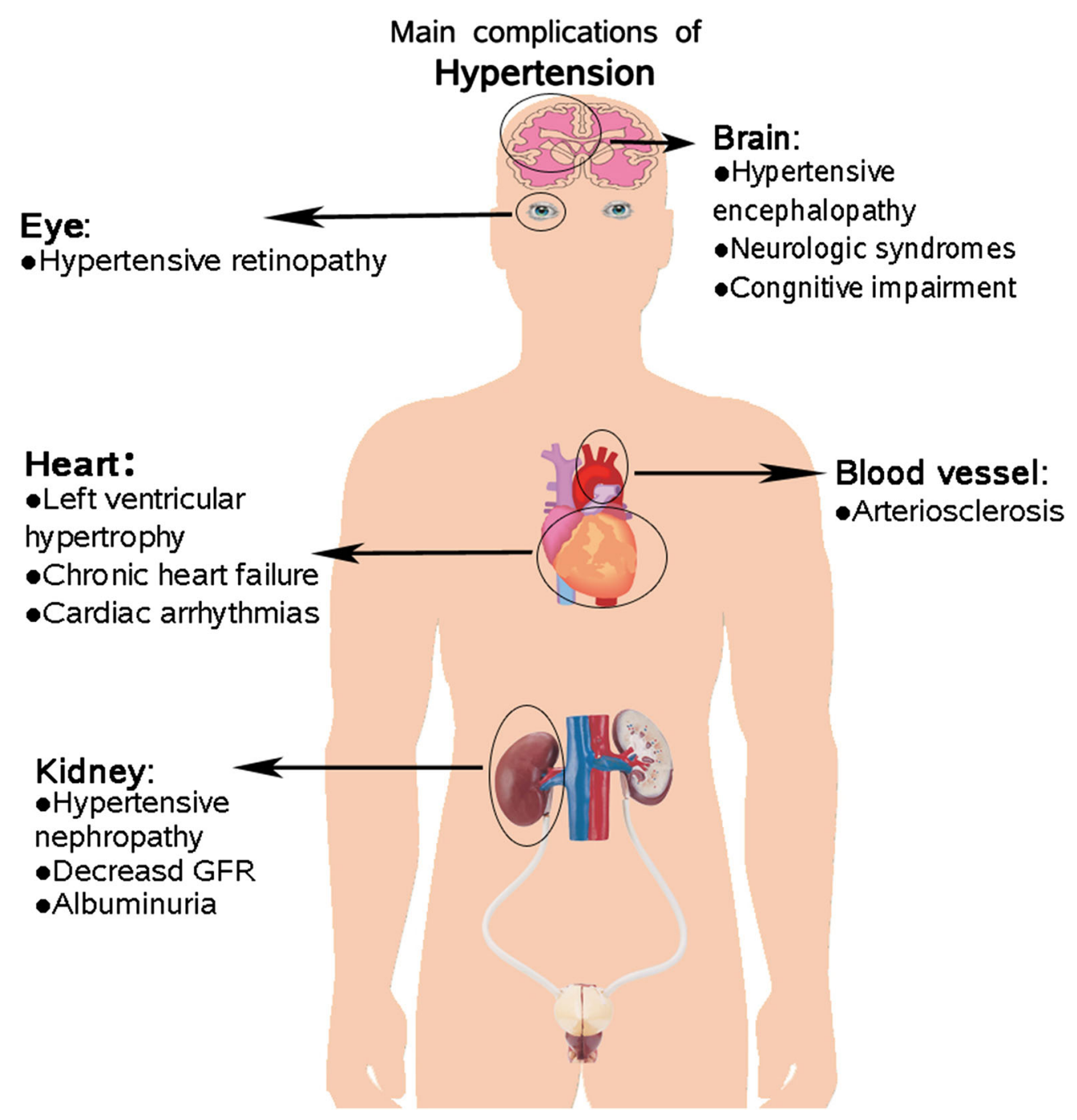

Fig. 1 Major compliances of hypertension

was found that renin acts on a serum $\alpha 2$-globulin produced by the liver called angiotensinogen, which has 453 amino acids. The cleavage product is a small peptide called angiotensin I (Ang I), which has ten amino acids, and is cleaved by angiotensin-converting enzyme (ACE) to form the eight-amino-acid angiotensin II (Ang II, Asp-Arg-Val-Tyr-Ile-His-Pro-Phe). The most important receptor for Ang II is called angiotensin II receptor type 1 or $\left(\mathrm{AT}_{1}\right)$.

In the 1970s, it was found that Ang II raised $\mathrm{BP}$, and individuals with high levels of renin activity in plasma were at increased risk of cardiovascular disease [17]. The physiological functions of angiotensin II in the cardiovascular system have been fully explained and presented in various review articles [18-21]. The major actions of Ang II include potent vasoconstriction effects of arterioles throughout the body; decreased renal blood flow and increased tubular sodium reabsorption and water retention. Ang II stimulates aldosterone and anti-diuretic hormone $(\mathrm{ADH})$ secretion via the hypothalamus pituitary-adrenal axis or the local system (Fig. 2). With the introduction of ACE inhibitors such as captopril in the late 1970s [22], it was confirmed that pharmaceuticals that reduce Ang II activity could treat hypertension.

The first attempts to develop useful Ang II receptor $\left(\mathrm{AT}_{1}\right)$ antagonists focused on 


\section{RAS system and the mechanism of ACEI/ARB drugs}

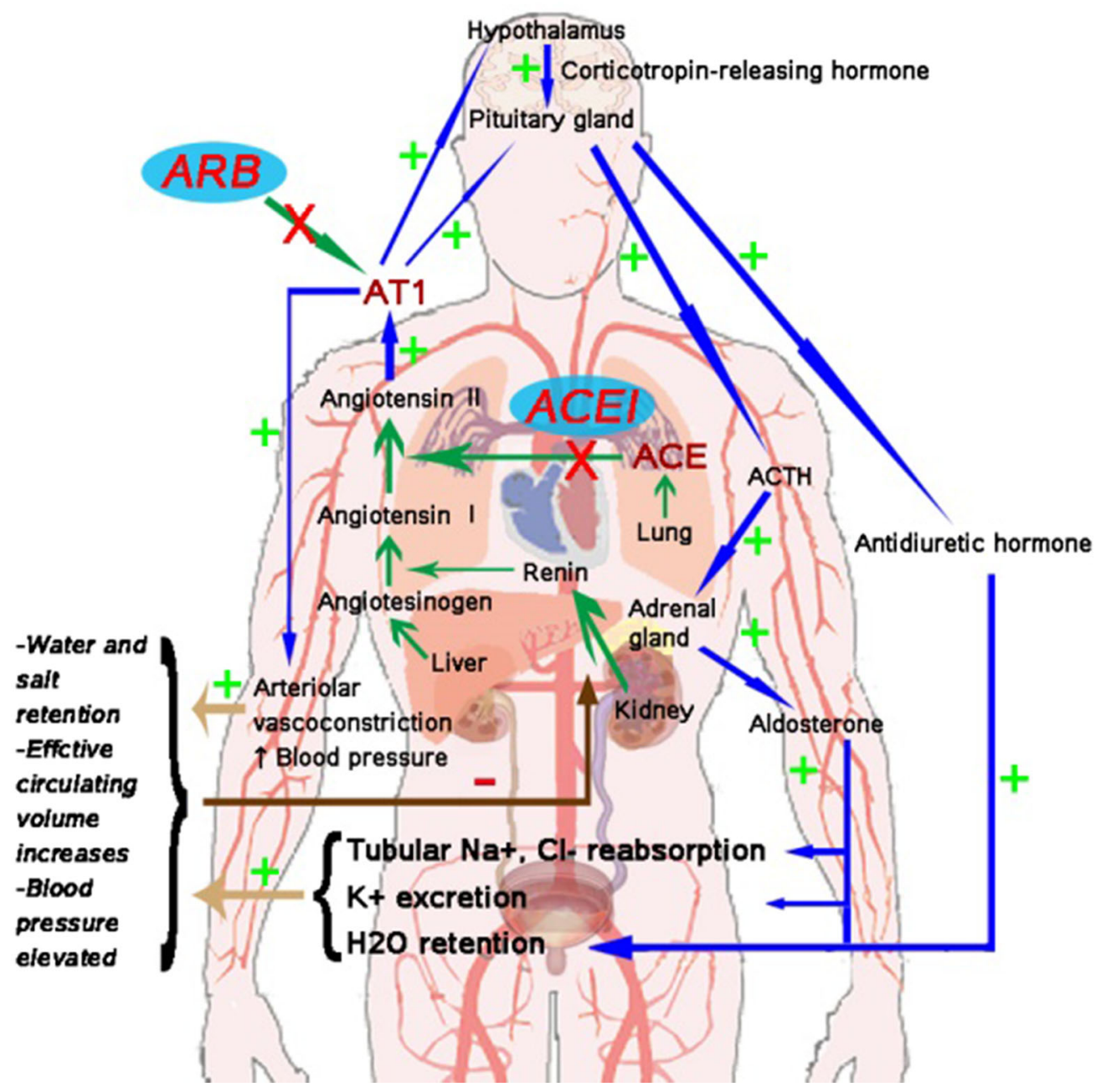

Fig. 2 The mechanism of ACEI and ARB function in the RAS system

angiotensin peptide analogs. Saralasin contains amino acid replacements by sarcosine, valine, and alanine (Sar-Arg-Val-Tyr-Val-His-Pro-Ala) and is a partial agonist of the Ang II receptor [23].

In the early 1980s it was found that some imidazole-5-acetic acid derivatives diminished blood pressure rise after administration of Ang II in rats [24]. Two compounds, S-8307 and S-8308, were later found to be promising non-peptide Ang II receptor antagonists. Structural modifications were made, and the orally active, potent, and selective nonpeptide $\mathrm{AT}_{1}$ receptor blocker losartan was developed. In 1995 losartan was approved for clinical use in the US, and since then seven additional "sartans" have been approved (irbesartan, olmesartan, candesartan, valsartan, fimasartan, eprosartan, and azilsartan) [25]. Three of these sartans (olmesartan, azilsartan, and candesartan) are usually administered as ester prodrugs. The goal of using an ester prodrug is to improve on the ADME (absorption, distribution, metabolism, excretion) properties of the drug. In the case of olmesartan and azilsartan the prodrug moiety is medoxomil (5-methyl-2-oxo-1,3-dioxol-4-yl)-methyl ester. olmesartan 
medoxomil is hydrolyzed by several esterase enzymes in the intestines releasing the active drug, olmesartan, which is easily absorbed [26].

\section{Choice of Medications for Hypertension}

The first-choice of medication to be employed for primary hypertension patients with additional complications such as heart failure, coronary artery disease, and diabetes mellitus, etc., are ACEI; this is accordance with guidelines recommended by several medical societies. However, since ACEI drugs inhibit ACE, which also degrades bradykinin, bradykinin therefore accumulates and can cause angioedema or angioneurotic edema. This is a rapid swelling of the dermis, subcutaneous tissue, mucosa, and submucosal tissues (similar to an allergic reaction) and can be life-threatening due to airway blockage (Table 1).

Sartans or ARBs are known for their excellent side-effect profiles, which have been shown to be similar to those of placebos in several clinical trials. Therefore, ARBs are used in some cases when patients who are not tolerant to ACEIs. ARBs can avert the incidence of this side effect, and thus can also achieve better efficacy in controlling BP. Previous studies suggested that in addition to the antihypertensive effect, the ARB might directly prevent organ damage [27].

Mostly, the combination therapy choice with ARB for mild-to-severe hypertensive patients range from $\mathrm{CCB}$ to diuretics, which are two strongly effective and tolerable agents. Since there is no report of severe drug conflict among ARB, CCB, and diuretics, concomitant use of these anti-hypertensive that act through different pharmacological pathways is recommended for patients with moderate-to-severe hypertension and those who do not reach BP goals with monotherapy [28].

Moreover, some clinical trials and meta-analyses that have recently been published have suggested that ARBs are not particularly effective in preventing cardiovascular events, like severe cardiovascular diseases (CVD), and may also have side effects such as adverse renal effects [29-36]. This controversy about the efficacy of ARBs in treating hypertension and preventing cardiovascular events emphasizes the necessity to select the best agents for each particular patient for BP control [37]. Some studies have brought into question the use of ARBs for treating patients with severe CVD or preventing patients from developing CVD, because ARBs did not decrease the morbidity and mortality of the study patients [38-41]. For instance, one meta-analysis explored the efficacy of ARBs in the prevention of myocardial infarction and other cardiovascular outcomes. The results showed, when compared with placebo or active treatment, that ARBs were ineffective in the prevention of myocardial infarction (RR 0.99, 95\% CI 0.92-1.07), death, cardiovascular death, or angina pectoris [38]. Moreover, another meta-analysis investigated the efficacy of ACEI and $\mathrm{ARB}$ in the prevention of CVD in patients with diabetes and hypertension and revealed that ACEI could significantly reduce the risk of all-cause mortality by $13 \%$ (RR $0.87 ; 95 \%$ CI $0.78-0.98)$, incidence of cardiovascular deaths by $17 \%(0.83 ; 0.70-0.99)$, and major cardiovascular events by $14 \%(0.86 ; 0.77-0.95)$. However, ARB did not show the same advantages [41].

Therefore, the choice of antihypertensive drugs significantly depends on the individual patients' medical condition. For patients with mild-to-moderate hypertension who are also intolerant to ACEI, ARB is a good choice for BP control. For patients with primary hypertension who are tolerant to ACEI and have CVD such as heart failure ACEI should be recommended due to the fact that ACEI has a better ability to protect renal function and prevent the incidence of CVD.

\section{The Pharmacology of Olmesartan}

\section{Pharmacodynamics Properties of Olmesartan Medoxomil}

Olmesartan medoxomil is a white to light yellowish-white powder or crystalline powder with a molecular weight of 558.6, and practically insoluble in water and sparingly soluble in methanol [42]. It is an angiotensin II type 1 receptor antagonist that inhibits the actions of angiotensin II on the renin-angiotensin-aldosterone system, 


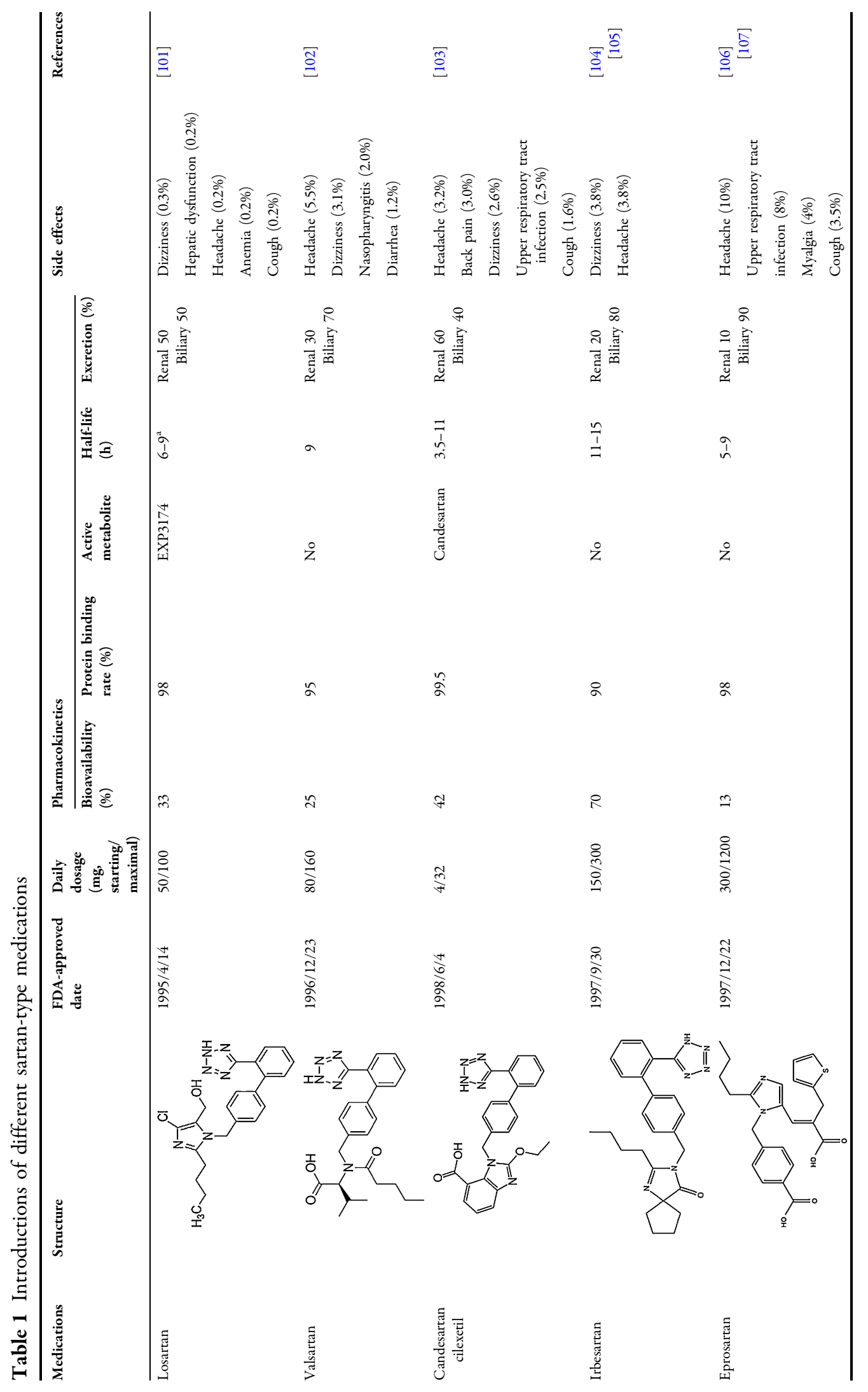




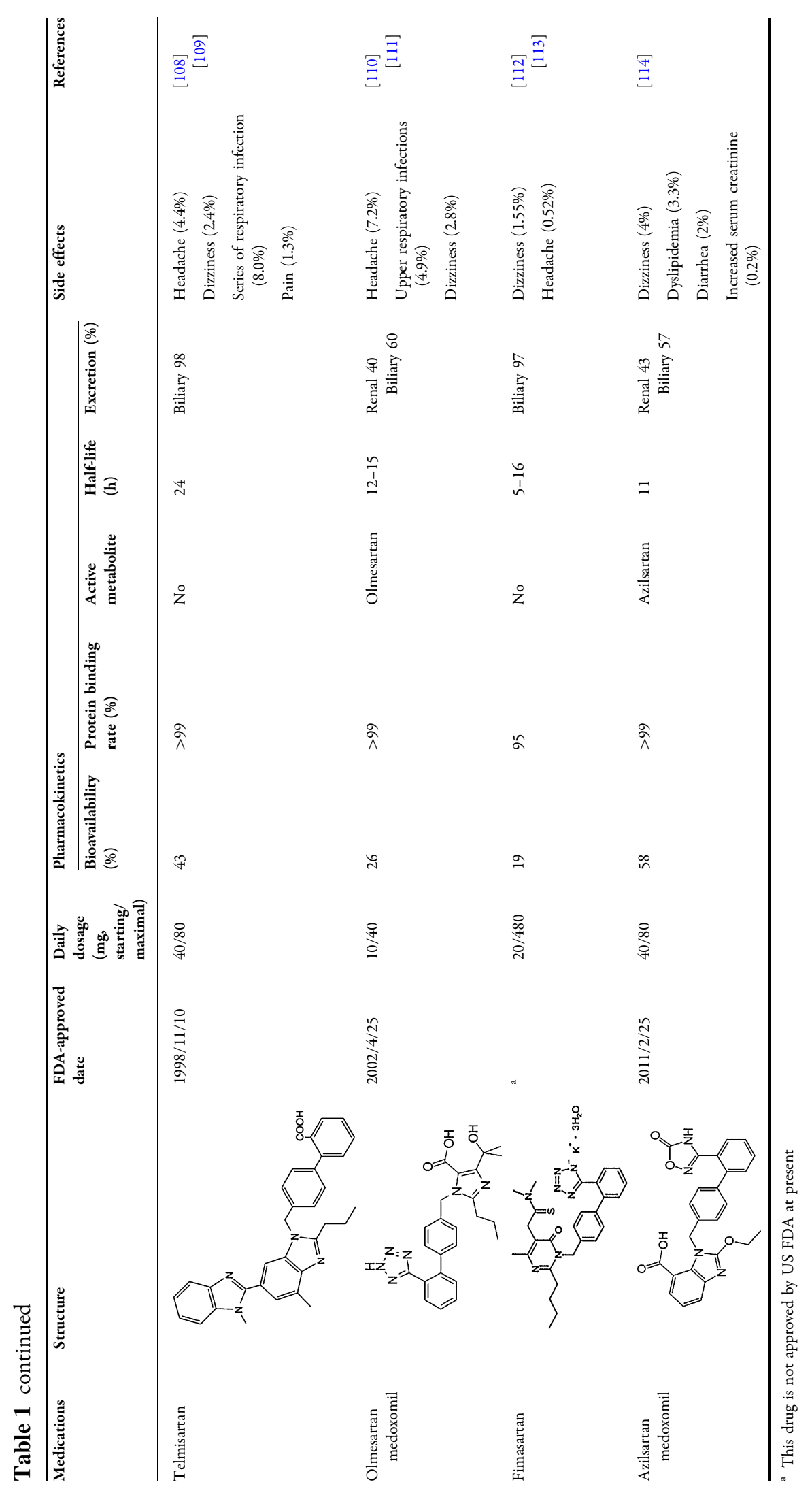


which plays a key role in the pathogenesis of hypertension. Oral olmesartan, $10-40 \mathrm{mg}$ once daily, is recommended for the treatment of adult patients with hypertension [43]. Besides, olmesartan blocks the action of angiotensin II by binding with high selectivity to the angiotensin II type 1 receptor and not to angiotensin II type 2 receptor [44]. It binds to the type 1 receptor with a high degree of insurmountability and with greater affinity than most other ARBs. According to studies in vivo, olmesartan dose-dependently antagonized the vasoconstrictor and pressure responses induced with angiotensin II [45].

\section{Pharmacokinetics Properties of Olmesartan Medoxomil}

Olmesartan is rapidly and completely bio-activated by ester hydrolysis to olmesartan during absorption from the gastrointestinal tract. Olmesartan is rapidly absorbed following oral administration and is completely metabolized to the pharmacologically active metabolite. Steady-state levels are achieved within 3-5 days and no accumulation in plasma occurs with once-daily dosing. The absolute bioavailability of olmesartan is approximately $26 \%$. After oral administration, the peak plasma concentration $\left(C_{\max }\right)$ of olmesartan can be reached after 1-2 $h$, and food does not affect the bioavailability of olmesartan. In addition, the volume of distribution is approximately $17 \mathrm{l}$. Olmesartan is highly bound to plasma proteins (99\%) and does not penetrate red blood cells [46].

To our knowledge, olmesartan, as an orally administered prodrug, is able to rapid and complete converted into olmesartan during absorption, and is virtually no further metabolism of olmesartan [47]. Total plasma clearance of olmesartan is $1.3 \mathrm{l} / \mathrm{h}$, with a renal clearance of $0.6 \mathrm{l} / \mathrm{h}$. No components other than olmesartan were detected in plasma following oral administration of radiolabeled olmesartan in healthy volunteers [48]. Besides, $C_{\max }$ of olmesartan increases linearly with single oral doses of olmesartan between 10 and $160 \mathrm{mg}$ [49]. Approximately $35-50 \%$ of the absorbed dose is recovered in urine while the remainder is eliminated in feces via the bile [50].

\section{The Clinical Use of Olmesartan Alone or in Combination}

\section{Monotherapy of Olmesartan}

The open-label, non-comparative, multi-centric WINOVER study was reported concerning the patient condition of olmesartan monotherapy [51]. In this study, 8940 adults patients ( $>18$ years) with essential hypertension as well as co-morbidities such as angina, diabetes mellitus, or dyslipidemia were recruited. Patients were treated with olmesartan tablet 20 or $40 \mathrm{mg}$ once daily for 6 months. After 3 and 6 months from initiation of treatment with olmesartan, the reduction of systolic blood pressure (SBP) $<140 \mathrm{mmHg}$ and diastolic blood pressure (DBP) $<90 \mathrm{mmHg}$ was observed as primary outcome. As a result, baseline SBP/DBP of $164 / 100 \mathrm{mmHg}$ was reduced to $153 / 93,145 / 89,134 / 84$, and $130 / 82 \mathrm{mmHg}$ at the end of 15 days, 1,3 , and 6 months, respectively, both of which were statistically significant $(p<0.0001)$. Besides, the consistent increase of percentage of responders for both SBP and DBP from the 15th day to 6 months was observed. The mild-to-moderate AEs rate was $0.08 \%$ in all patients, and with no incidence of serious cases. As for the treatment results at 6 months, $96.49 \%$ and $96.48 \%$ of patients was rated as good when assessed by the treating physicians, respectively, with no severe clinical outcomes occurring. Another similar study was the OLMEBEST study [52]. This European, multinational, double-blind study also revealed that olmesartan (20 $\mathrm{mg}$ tablet) resulted in a mean reduction of $11.8 \mathrm{mmHg}$ in mean sitting diastolic blood pressure and $17.1 \mathrm{mmHg}$ in mean sitting systolic blood pressure from baseline. The adverse event rate was $30.9 \%$, and the majority of these events were mild. It was also highlighted that olmesartan medoxomil $20 \mathrm{mg} /$ day was well tolerated, with no severe clinical outcomes reported.

When compared with candesartan, olmesartan performed more effectively in reducing daytime and 24-h DBP and SBP revealed by Brunner's study [53]. This randomized, double-blind, parallel-group study included 643 patients aged 19-86 years with mainly mild-to-moderate essential hypertension, which was conducted at 44 centers in Germany, 
Poland, and the Czech Republic. In the olmesartan group, the result showed that mean decreases by $6.7,8.4$, and $9.3 \mathrm{mmHg}$ from baseline in daytime DBP, after the treating time of week 1,2 , and 8 , respectively. The result is superior to the candesartan group $(p<0.0126)$. The mean 24-h DBP/SBP also showed significant advantages in favor of olmesartan treatment. No severe adverse clinical events occurred.

As for the comparison for other ARBs, Oparil's [54] study showed that the reduction of sitting cuff DBP with olmesartan $(11.5 \mathrm{mmHg})$ was significantly greater than with losartan, valsartan, and irbesartan (8.2, 7.9, and $9.9 \mathrm{mmHg}$, respectively). Drug-related AEs and discontinuation were rare among all groups, with no severe adverse events reported. The authors concluded that compared with other ARBs, olmesartan is more effective in reducing cuff DBP in patients with essential hypertension. However, Smith DH's study [55] suggested that olmesartan was significantly more effective than losartan or valsartan, its effects on mean decrease from baseline in ambulatory blood pressure $(\mathrm{ABP})$ and its goal rates were numerically better.

There were also several studies comparing olmesartan with amlodipine for mild-to-moderate hypertension. Chrysant's study [56] revealed that though mean reductions in ambulatory and seated BP were similar between the two agents group and both were well tolerated at the recommended starting dose, more patients in the olmesartan group achieved the SBP goal of $<130 \mathrm{mmHg}$ and the DBP goal of $<85 \mathrm{mmHg}$. This conclusion was also confirmed by Chrysant's further study [57].

Omboni performed a pooled analysis from two recent identically designed trials [58]. The two trials compared the head-to-head efficacy and safety of olmesartan and ramipril in elderly patients with essential hypertension with or without metabolic syndrome. After 12 weeks of treatment, BP reductions were greater $(p<0.05)$ with olmesartan (SBP 17.0 mmHg; 95\% CI 18.4, 15.6; DBP $9.6 \mathrm{mmHg}$; 95\% CI 10.4, 8.8) than with ramipril (SBP $14.7 \mathrm{mmHg}$; 95\% CI 16.1, 13.2; DBP $8.4 \mathrm{mmHg}$; 95\% CI 9.2, 7.6) in patients with metabolic syndrome. The BP normalization rates of olmesartan were also greater than ramipril ( 46.0 vs. $35.8 \%, p<0.01$ ) in these patients. The same result also occurred in patients without metabolic syndrome and in the subgroup of patients with valid $A B P$ recordings and metabolic syndrome. As for the drug-related AEs, the proportion of patients was comparable with (olmesartan 2.4 vs. ramipril $2.8 \%$ ) and without (olmesartan 3.5 vs. ramipril $3.7 \%$ ) metabolic syndrome. In conclusion, olmesartan provides more effective BP control than ramipril in elderly hypertensive patients with and without metabolic syndrome was made [59].

Also, some retrospective re-studies compared the efficacy and safety of olmesartan monotherapy with other ARBs, ACEIs, CCBs, diuretics, and $\beta$-blockers monotherapy, in which the results revealed that olmesartan showed greater clinical superiority to the other categories above $[59,60]$.

\section{Olmesartan/Amlodipine Versus Amlodipine or Olmesartan}

A randomized, double-blinded clinical trial investigated the efficacy and safety of olmesar$\tan (10 \mathrm{mg} / 20 \mathrm{mg} / 40 \mathrm{mg})$ and amlodipine ( $5 \mathrm{mg} / 10 \mathrm{mg}$ ) alone and with all possible combinations of variable concentrations [61, 62]. The primary efficacy variable was the change from baseline in mean sitting diastolic blood pressure (SeDBP) and mean sitting systolic blood pressure (SeSBP) at week 8. The proportion of patients achieving BP targets at week 8 $(<140 / 90$ and $<120 / 80 \mathrm{~mm} \mathrm{Hg})$ was also assessed. The conspicuous features of this study are that all of these efficacy assessments were applied to pre-specified subgroups including race (black and non-black), diabetes status, age ( $<65$ years, greater than or equal to 65 years) and baseline body mass index (baseline $30 \mathrm{~kg} /$ $\mathrm{m}^{2}$ ) and the data were analyzed between sub-groups. According to the results, the reductions of both SeDBP and SeSBP were significant for all olmesartan monotherapy $(p<0.05)$, amlodipine monotherapy $(p<0.0001)$ and amlodipine/ olmesartan combination therapy $(p<0.0001)$ regimens by week 8 . Specially, the amlodipine/ olmesartan combination therapy with dosage of 10 and $40 \mathrm{mg}$ /day achieved the greatest reductions in mean sitting blood pressure in all 
subgroups except SeSBP in non-Blacks group. As for the safety profiles, the tolerability of subgroups with difficult-to-treat hypertension were similar to their more easily treated counterparts as well as the monotherapy-treated cohorts. Only one serious adverse event (cerebrovascular accident) was reported, occurring in a black, obese female patient aged $<65$ years with type II diabetes in the olmesartan medoxomil $20 \mathrm{mg}$ /day group (Table 2).

A series of articles have reported that olmesartan/amlodipine combination produced benefits in increasing insulin sensitivity and decreasing inflammatory markers compared to any of them, which can tremendously benefit the hypertensive patients with multiple symptoms [63-67]. Sievers's study found that combined treatment with olmesartan and amlodipine attenuated atherosclerotic lesion progression, possibly due to anti-inflammatory mechanisms, even in advanced atherosclerosis [68].

\section{Olmesartan/Azelnidipine Versus Candesartan/ Amlodipine}

ARBs and CCBs are often co-administered for treating hypertension. Former studies have revealed that RAS inhibitors (ARB and ACEI) and a CCB effectively decreased central SBP by reducing arterial wave reflection [69]. Similarly, the J-CORE study by Matsui [70] has fully demonstrated that compared to the olmesartan (20 mg)/HCTZ (12.5 mg), olmesartan (20 mg)/ azelnidipine (16 mg) combination resulted in greater reductions in central SBP and arterial stiffness, although there is no significant difference between the two combinations in 24-h SBP.

To determine which combination performed better, Daikuhara [71] conducted the OLCA study, which was an open-label randomized study aimed at untreated diabetic hypertensive patients. At the beginning, 300 patients were randomized to have either olmesartan (20 mg/day) or candesartan (8 mg/day), with 150 participants in each group. There were no differences between the two groups. The 115 patients in the olmesartan group and 121 patients in the candesartan group who did not achieve the anti-hypertensive goal (130/
$80 \mathrm{mmHg}$ ) within 12 weeks were assigned to received add-on CCB therapy, treated with azelnidipine $16 \mathrm{mg} /$ day or amlodipine $5 \mathrm{mg} /$ day for 24 weeks. There were similar proportions of patients using insulin or oral antidiabetic drugs in both groups, which did not affect the result of this study. The result showed that no significant difference between the olmesartan and candesartan groups was found in the first 12 weeks. As a result, the olmesartan group achieved greater effect in controlling blood pressure. In the following 24 weeks, mean deduction in clinic-measured SBP/SDP of olmesartan and candesartan group was $15.3 \pm 4.8 / 7.1 \pm 3.2 \mathrm{mmHg}$ (both $p<0.01$ ) and $14.5 \pm 4.6 / 6.7 \pm 3.1 \mathrm{mmHg}$ (both $p<0.01$ ), respectively. Also, the deduction of early morning BP was $16.7 \pm 5.0 / 8.8 \pm 3.0 \mathrm{mmHg}$ (both $p<0.01$ ) and $13.0 \pm 4.6 / 6.4 \pm 3.1 \mathrm{mmHg}$ (both $p<0.01$ ). As for the clinical outcome, no severe cases occurred, and none of these patients withdrew due to adverse events. All of these data indicate that both olmesartan and candesartan had good antihypertensive effects, with olmesartan possessing a more significant antihypertensive effect. Furthermore, the olmesartan group achieved significantly greater home-measured early morning BP reduction than the candesartan group $(p<0.05)$.

\section{Olmesartan/Amlodipine Versus Aliskiren/ Amlodipine}

Axthelm et al. designed a study to investigate the efficacy of aliskiren and amlodipine combination therapy in hypertensive patients whose BP is not adequately controlled by the combination of olmesartan and amlodipine [72]. This study had two 4-week phases, which were noted as phase 1 and phase 2 . Each of these had the treatment protocol of olmesartan $40 \mathrm{mg} /$ amlodipine $10 \mathrm{mg}$ and aliskiren $300 \mathrm{mg} /$ amlodipine $10 \mathrm{mg}$, respectively. The author switched patients from phase 1 to phase 2, whose BPs were not adequately controlled. Those whose BP was not controlled in phase 2 would be arranged for an optional 4-week combination treatment of aliskiren $300 \mathrm{mg} /$ amlodipine $10 \mathrm{mg} / \mathrm{HCTZ} 12.5 \mathrm{mg}$. As a result, 342 patients who were included in phase 1 have a decrease of SBP/DBP by $24.5 / 14.5 \mathrm{mmHg}$. In 


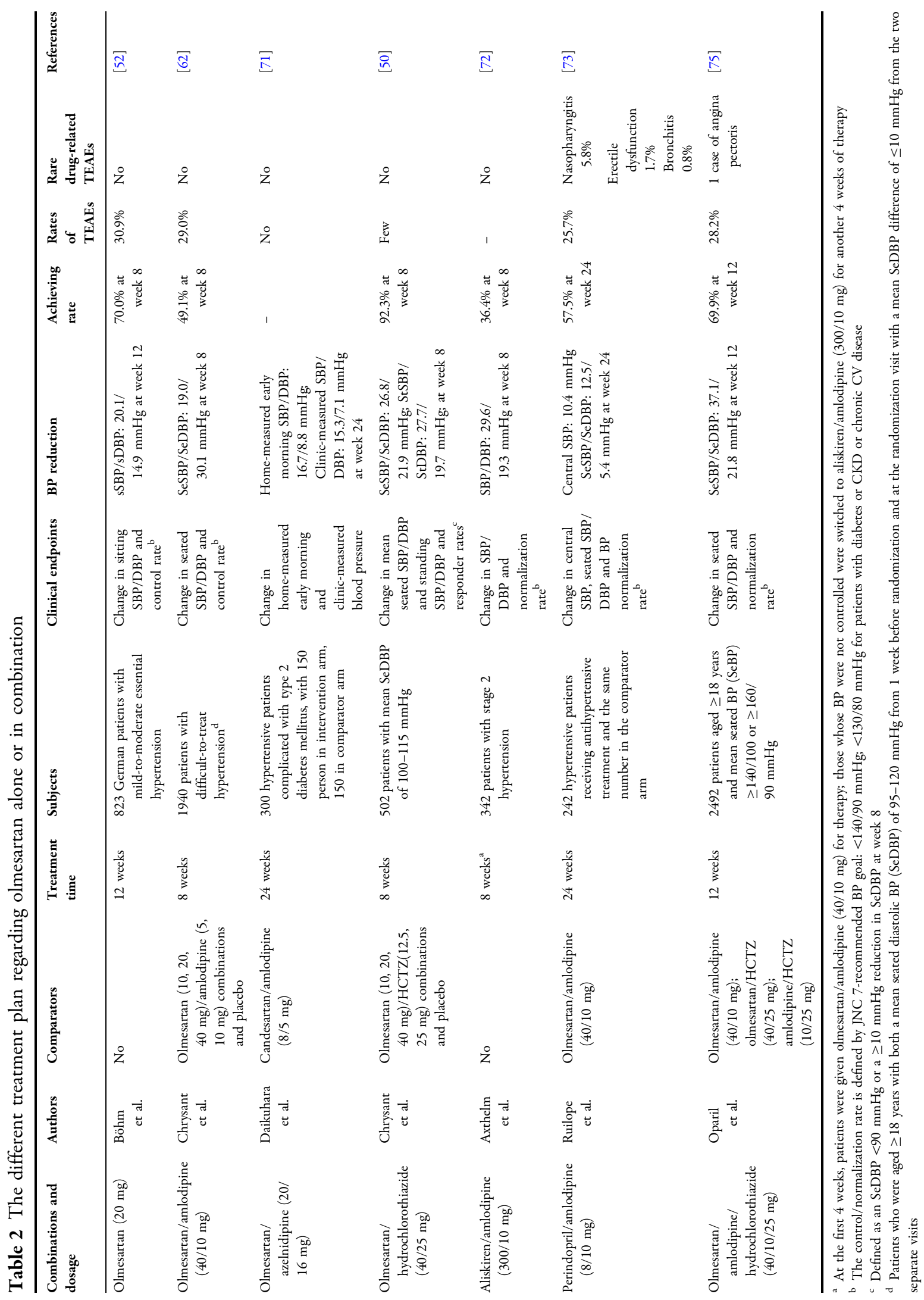


phase 2, 187 patients with uncontrolled hypertension at the end of phase 1 obtained a further SBP/DBP reduction of $5.1 \mathrm{mmHg} / 4.8 \mathrm{mmHg}$ $(95 \%$ CI $3.7,6.5) /(95 \%$ CI 3.8, 5.8) with the SBP/ DBP responder rates by $44.4 \% / 51.3 \%$ and SBP and DBP normalization by $36.4 \%(p<0.0001)$. The 65 patients who received the optional treatment obtained a further decrease of SBP/ DBP by $8.1 / 6.7 \mathrm{mmHg}(p<0.0001)$. No deaths or severe AEs were reported. In conclusion, the aliskiren/amlodipine and aliskiren/amlodipine/ hydrochlorothiazide combination had achieved a clinically and statistically greater reduction in BP when the patient's BP could not be normally controlled by the olmesartan and amlodipine combination.

\section{Olmesartan/Amlodipine Versus Perindopril/ Amlodipine}

The SEVITENSION study compared the effects of perindopril/amlodipine and olmesartan/amlodipine in decreasing central aortic blood pressure [73]. Six hundred patients were enrolled in this study. At the beginning, the patients received amlodipine $10 \mathrm{mg}$ during a $2-4$ weeks run-in, and 486 of them were randomized to receive 24 weeks of double-blind combination treatment, with 244 patients having olmesartan/amlodipine $40 / 10 \mathrm{mg}$ and 242 patients having perindopril/amlodipine $8 / 10 \mathrm{mg}$, with optional hydrochlorothiazide added in patients with inadequate BP control at weeks 4, 8, or 12 . The study design is presented in Fig. 3 . The absolute change in central systolic blood pressure (CSBP) from baseline to the final value was set as the primary efficacy variable. As for the result, the CSBP reduction of olmesartan/amlodipine group was higher than perindopril/ amlodipine group, with the BP reduced by $14.5 \pm 0.83 \mathrm{mmHg}$ versus $10.4 \pm 0.84 \mathrm{mmHg}$. Also, olmesartan/amlodipine recipients achieved significantly greater BP normalization rates than the perindopril/amlodipine recipients ( 75.6 vs. $57.5 \%, p<0.0001)$. Notably, each treatment was well tolerated, and the proportion of patients with $\geq 1$ drug-related treatment-emergent adverse events (TEAEs) was comparable to the olmesartan/amlodipine (25.0\%) and perindopril/amlodipine (25.7\%) groups, while the patients that discontinued treatment due to a drug-related TEAE was 5.7\% in olmesartan/amlodipine group compared with $7.5 \%$ in the perindopril/amlodipine group. No severe clinical outcome was reported. In conclusion, this study strongly suggested that the combination of olmesartan/amlodipine was superior to perindopril/amlodipine in reducing CSBP as well as maintaining a higher rate of BP normalization. The post hoc analysis of this study further also supported the conclusion in hypertensive patients with diabetes [74].

\section{Olmesartan/Hydrochlorothiazide Versus Olmesartan or Hydrochlorothiazide}

In a randomized, double-blind, factorial design study [50], Chrysant investigated the efficacy of olmesartan $(10,20, \quad$ or $40 \mathrm{mg} /$ day $) /$ hydrochlorothiazide (12.5 or $25 \mathrm{mg} /$ day) with accordingly six possible combination versus each of the agents alone. In total, 502 patients in 12 groups including placebo received their treatment regimens throughout the 8-week experiment. The change in mean trough SeDBP from baseline at week 8 was set as the primary endpoint. The author did not compare BP reductions with different combination doses, which was probably a limitation. The result still suggested that olmesartan/HCTZ led to greater reductions in both SeDBP and SeSBP at week 8 than each of the agents and dosage alone. The reductions of SeSBP/SeDBP in the combined group of olmesartan/HCTZ 20/12.5 mg, olmesartan/HCTZ 40/25 mg, and placebo were 3.3/ $8.2 \mathrm{mmHg}(95 \%$ CI $6.0,10.3) /(95 \%$ CI 6.0 , 10.3), 20.1/16.4 mmHg (95\% CI 17.1, 23.0)/ (95\% CI 14.7, 18.1), and 26.8/21.9 mmHg (95\% CI $22.8,30.8) /(95 \%$ CI 19.5, 24.3), respectively. The result indicated that olmesartan/HCTZ $40 / 25 \mathrm{mg}$ combination achieved the greatest reduction, and the highest responder rate $(92.3 \%)$ and control rates (79.5\% for diastolic and $87.2 \%$ for systolic) were also observed in the olmesartan/HCTZ 40/25 mg/day group. As for drug safety, investigators noted that all dosages of monotherapy and combination therapy were safe and well tolerated, and no significant incidence of treatment-emergent adverse effects was reported. The overall discontinuation rate was $2.0 \%$ and was not the result of an $\mathrm{AE}$ or related to dosage of any study 


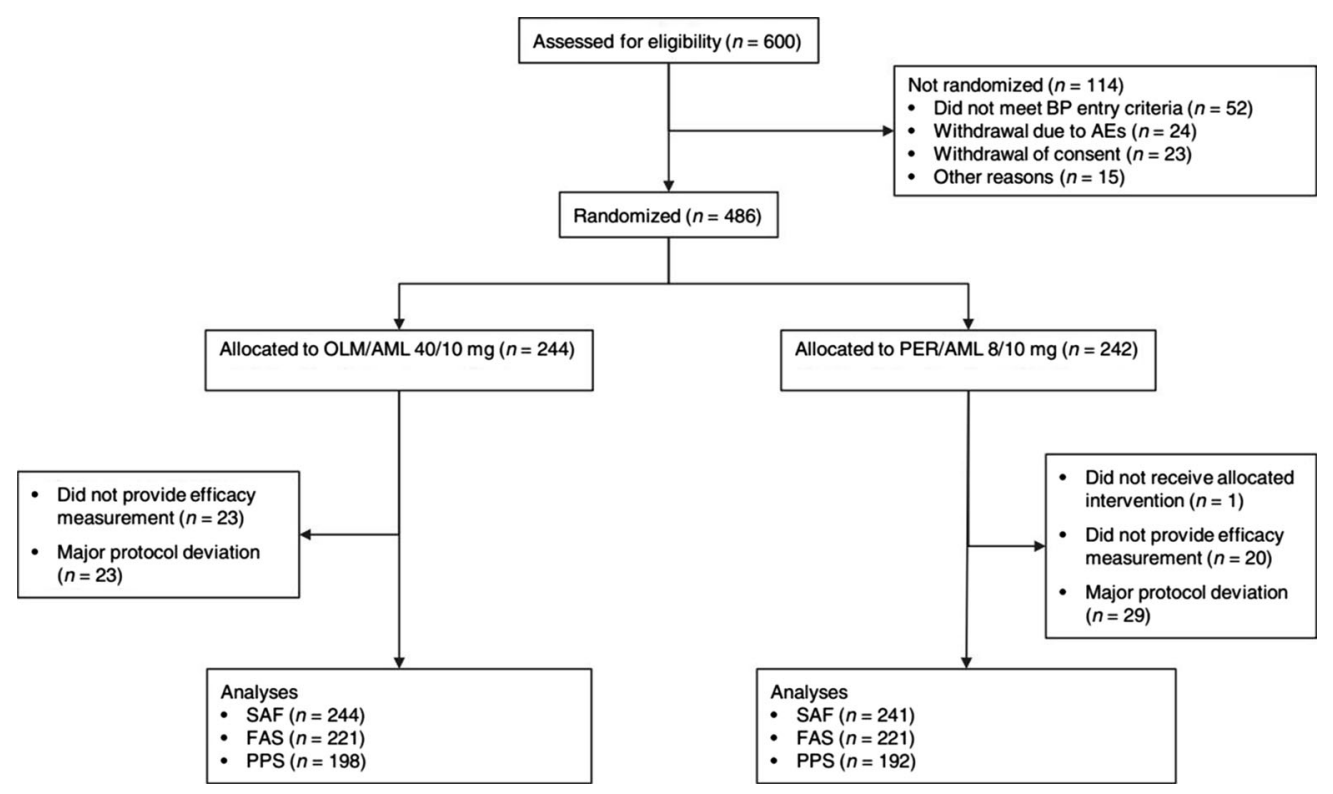

Fig. 3 The study design and treatment procedure of the SEVITENSION study [73]

medication. No severe clinical outcomes were reported.

\section{Olmesartan/Amlodipine/Hydrochlorothiazide}

It is recommended that patients with uncontrolled hypertension treated with two antihypertensive agents may require a combination of three agents to achieve satisfied BP. Oparil conducted the TRINITY study [75] to determine whether the triple combination of olmesartan, amlodipine, and HCTZ had better efficacy and safety conditions compared with dual combinations in patients aged $\geq 18$ years who had moderate-to-severe hypertension, who have the SeSBP $\geq 140 / 100$ or $\geq 160 / 90 \mathrm{mmHg}$. The study design and detail is presented in Fig. 4. After a 3 -week washout period with no study medication and a 12-week double-blind treatment (olmesartan $40 \mathrm{mg} /$ amlodipine $10 \mathrm{mg} / \mathrm{HCTZ}$ $25 \mathrm{mg}$, olmesartan $40 \mathrm{mg} /$ amlodipine $10 \mathrm{mg}$, olmesartan $40 \mathrm{mg} / \mathrm{HCTZ} 25 \mathrm{mg}$, and amlodipine $10 \mathrm{mg} / \mathrm{HCTZ} 25 \mathrm{mg}$ ), the study found that triple combination treatment was associated with significantly greater mean reductions in seated BP compared with the dual combinations. The reduction of SeDBP and SeSBP in triple combination group is 21.8 and $37.1 \mathrm{mmHg}$, respectively. While in the dual combination group, the SeDBP and SeSBP reductions ranged from $15.1-18.0 \mathrm{mmHg}$ to $27.5-30.0 \mathrm{mmHg}(p<0.001)$, respectively. As for $\mathrm{BP}$ achieving rate, patients in triple combination treatment reached BP targets with significantly higher proportion compared to the dual combinations at week 12 (olmesartan/amlodipine/HCTZ: 69.9\%, olmesartan/amlodipine: 52.9\%, olmesartan/HCTZ: 53.4\%, and amlodipine/HCTZ: $\quad 41.1 \%$ respectively $[p<0.001])$. All of the treatments in this study were generally well tolerated, with $1.5 \%$ of patients experiencing serious AEs.

In the TRINITY ABP sub-study, the authors used the ABP monitoring (ABPM) method to compare the clinical benefits between the same triple combination and the same dual combination, in which they found that the triple combination demonstrated superior efficacy and sustained reductions in ABP compared with its dual-combination components. ABPM is currently recommended by the American Society of Hypertension as the best method for assessing cardiovascular risk in individuals with hypertension [76]. Therefore, the result supports the idea that triple combination therapy is better than the each of the dual combinations.

Another TRINITY sub-study revealed the fact that triple combination treatment could also 


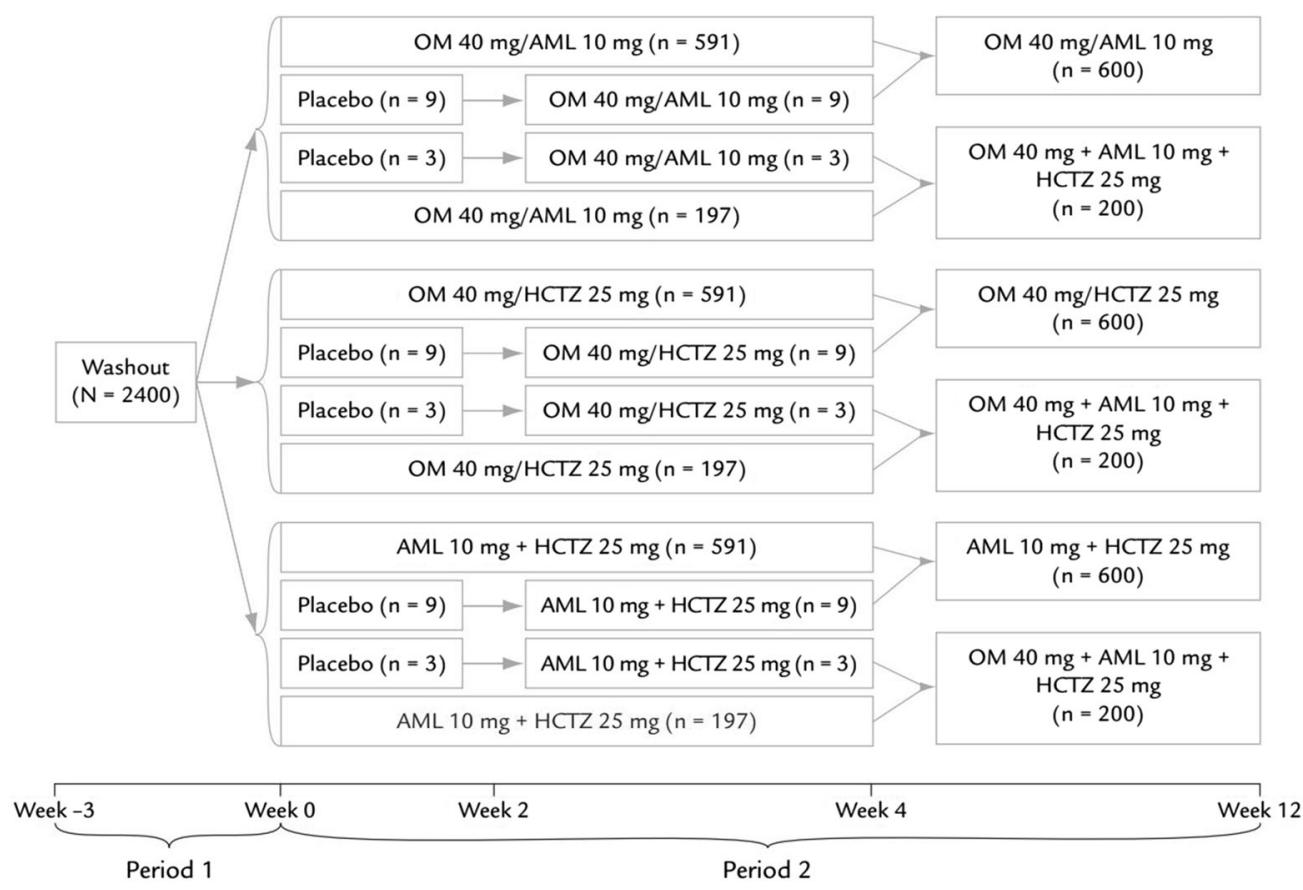

Fig. 4 Study design of the TRINITY study. OM olmesartan medoxomil, AML amlodipine besylate, HCTZ hydrochlorothiazide [75]

benefit patients with different pathological conditions, such as diabetes, chronic kidney disease, and chronic cardiovascular disease [56]. Factors like age, ethnicity, and race did not affect the treatment results in the triple combination group compared with the dual combination treatment group [77-80].

\section{Safety and tolerability}

Safety and tolerability for oral olmesartan in patients with moderate-to-severe hypertension were continually investigated $[81,82]$. An integrated analysis of efficacy and safety of olmesartan demonstrated that the AEs profile observed with olmesartan monotherapy and combination therapy was approximate to placebo, and dizziness was the only event that occurred more in patients with olmesartan comparing with placebo [11]. Also, olmesartan was with less AEs compared with valsartan, losartan, and amlodipine during the treatment period. Besides, AEs associated with the combination of olmesartan and HCTZ were generally mild-to-moderate in severity [83]. The safety of
olmesartan/HCTZ was well evaluated in 1243 hypertensive patients. As a result, treatment with olmesartan/HCTZ was well tolerated. Dizziness, flushed face, and upper respiratory tract infections were more often reported in olmesartan/HCTZ recipients than placebo recipients [84]. However, adverse events were generally mild, transient, and had no relationship with the dose of olmesartan/HCTZ. There was also no difference of AEs between olmesar$\tan /$ HCTZ and placebo among gender, age, and race groups.

The best-known severe adverse event associated with olmesartan is sprue-like enteropathy, according to several case reports and research articles [85-90]. Rubio-Tapia et al. firstly reported that 22 olmesartan recipients who suffered from chronic diarrhea could recover from the syndrome after stopping olmesartan therapy [91]. Generally, the symptoms of olmesartan-induced enteropathy are watery diarrhea, abdominal pain, weight loss, and nausea, and symptoms can be ameliorated after stopping the medication. Pathology studies showed clear inflammatory changes in the intestinal mucosa, 
such as villous blunting with near-complete villous atrophy of the small intestinal mucosa [88, 92-94]. Although the pathogenic mechanism of this disease remains unclear, some hypotheses were presented. Laniro et al. and Rubio-Tapia proposed that a cell-mediated delayed hypersensitivity reaction could be the plausible explanation for these changes $[95,96]$. Another hypothesis suggested that the mechanism of action could involve inhibition of the transforming growth factor beta (TGF- $\beta$ ) pathway leading to a breakdown of the intestinal immune homeostasis, thus causing a pathological variation [97]. Therefore, early identification of olmesartan-induced enteropathy patients is important, and prompt discontinuation of the medication is strongly recommended [98].

In addition, combined therapy using olmesartan has been reported to have a positive effect on heart rate variability, which is an independent risk factor in predicting the severity and prognosis of cardiovascular disease. It was also reported that the use of olmesartan had an obvious BP stabilization for elderly recipients, especially in controlling the morning BP surge [99]. In addition, patients with chronic renal diseases are not suggested to be suitable for combined therapy owing to increased AEs [100].

\section{CONCLUSIONS}

Olmesartan medoxomil, as an angiotensin II receptor antagonist, shows good efficacy in BP reduction and stabilization. When combined with HCTZ or amlodipine, olmesartan has a better effect on controlling $\mathrm{BP}$ and reducing the $\mathrm{AE}$ rate. In conclusion, olmesartan alone or in combination with other anti-hypertensive agents is effective and well tolerated for the management of hypertension in patients.

\section{ACKNOWLEDGEMENTS}

No funding or sponsorship was received for this study or publication of this article. Michael R. Hamblin was funded by the US NIH Grant
R01AI050875. All named authors meet the International Committee of Medical Journal Editors (ICMJE) criteria for authorship for this manuscript, take responsibility for the integrity of the work as a whole, and have given final approval for the version to be published.

Disclosures. Xiaoshen Zhang, Han Zhang, Yuxia Ma, Wenliang Che, and Michael R. Hamblin have nothing to disclose.

Compliance with Ethics Guidelines. The contents of this article are based on previously published studies and do not involve any new studies of human or animal subjects performed by any of the authors.

Data Availability. The datasets during and/ or analyzed during the current study are available from the corresponding author on reasonable request.

Open Access. This article is distributed under the terms of the Creative Commons Attribution-NonCommercial 4.0 International License (http://creativecommons.org/licenses/ by-nc/4.0/), which permits any noncommercial use, distribution, and reproduction in any medium, provided you give appropriate credit to the original author(s) and the source, provide a link to the Creative Commons license, and indicate if changes were made.

\section{REFERENCES}

1. Poulter NR, Prabhakaran D, Caulfield M. Hypertension. Lancet. 2015;386(9995):801-12.

2. Lim SS, et al. A comparative risk assessment of burden of disease and injury attributable to 67 risk factors and risk factor clusters in 21 regions, 1990-2010: a systematic analysis for the Global Burden of Disease Study 2010. Lancet. 2012;380(9859):2224-60.

3. Collaborators, G.B.D.R.F., et al. Global, regional, and national comparative risk assessment of 79 behavioural, environmental and occupational, and metabolic risks or clusters of risks in 188 countries, 1990-2013: a systematic analysis for the Global 
Burden of Disease Study 2013. Lancet 2015;386(10010):2287-323.

4. Kearney PM, et al. Global burden of hypertension: analysis of worldwide data. Lancet. 2005;365(9455):217-23.

5. Ong KL, et al. Prevalence, awareness, treatment, and control of hypertension among United States adults 1999-2004. Hypertension. 2007;49(1):69-75.

6. Wolf-Maier $\mathrm{K}$, et al. Hypertension prevalence and blood pressure levels in 6 European countries, Canada, and the United States. JAMA. 2003;289(18):2363-9.

7. Smith DH. Comparison of angiotensin II type 1 receptor antagonists in the treatment of essential hypertension. Drugs. 2008;68(9):1207-25.

8. Kreutz R. Olmesartan/amlodipine: a review of its use in the management of hypertension. Vasc Health Risk Manag. 2011;7:183-92.

9. Chobanian AV, et al. Seventh report of the Joint National Committee on prevention, detection, evaluation, and treatment of high blood pressure. Hypertension. 2003;42(6):1206-52.

10. Safar ME, Struijker-Boudier HA. New goals in hypertension management: target-organ protection beyond blood pressure lowering. Drugs 2003;63(Spec No 1):45-7.

11. Bramlage $P$, et al. Safety and effectiveness of a fixed-dose combination of olmesartan, amlodipine, and hydrochlorothiazide in clinical practice. Vasc Health Risk Manag. 2015;11:1-8.

12. Chobanian AV, et al. The seventh report of the Joint National Committee on prevention, detection, evaluation, and treatment of high blood pressure: the JNC 7 report. JAMA. 2003; 289(19):2560-72.

13. Mancia G, et al. 2007 Guidelines for the management of arterial hypertension: the task force for the management of arterial hypertension of the European Society of Hypertension (ESH) and of the European Society of Cardiology (ESC). Eur Heart J. 2007;28(12):1462-536.

14. Ogihara T, et al. The Japanese Society of Hypertension guidelines for the management of hypertension (JSH 2009). Hypertens Res. 2009;32(1):3-107.

15. Marks LS, Maxwell MH. Tigerstedt and the discovery of renin. An historical note. Hypertension. $1979 ; 1(4): 384-8$.

16. Van Epps HL. Harry Goldblatt and the discovery of renin. J Exp Med. 2005;201(9):1351.
17. Burnier M, Brunner HR. Angiotensin II receptor antagonists. Lancet. 2000;355(9204):637-45.

18. Yee AH, Burns JD, Wijdicks EF. Cerebral salt wasting: pathophysiology, diagnosis, and treatment. Neurosurg Clin N Am. 2010;21(2):339-52.

19. Reid IA. The renin-angiotensin system and body function. Arch Intern Med. 1985;145(8):1475-9.

20. Unger T. The role of the renin-angiotensin system in the development of cardiovascular disease. Am J Cardiol. 2002;89(2, Supplement 1):3-9.

21. Paul M, Poyan Mehr A, Kreutz R. Physiology of local renin-angiotensin systems. Physiol Rev. 2006;86(3):747-803.

22. Smith CG, Vane JR. The discovery of captopril. FASEB J. 2003;17(8):788-9.

23. Guimond MO, et al. Saralasin and sarile are AT2 receptor agonists. ACS Med Chem Lett. 2014;5(10):1129-32.

24. Timmermans PB, et al. Nonpeptide angiotensin II receptor antagonists: a novel class of antihypertensive agents. Blood Vessels. 1990;27(2-5):295-300.

25. Michel MC, et al. A systematic comparison of the properties of clinically used angiotensin II type 1 receptor antagonists. Pharmacol Rev. 2013;65(2):809-48.

26. Ishizuka T, et al. Paraoxonase 1 as a major bioactivating hydrolase for olmesartan medoxomil in human blood circulation: molecular identification and contribution to plasma metabolism. Drug Metab Dispos. 2012;40(2):374-80.

27. Ciulla MM, et al. Different effects of antihypertensive therapies based on losartan or atenolol on ultrasound and biochemical markers of myocardial fibrosis: results of a randomized trial. Circulation. 2004;110(5):552-7.

28. Ruilope LM, et al. Efficacy and tolerability of combination therapy with valsartan plus hydrochlorothiazide compared with amlodipine monotherapy in hypertensive patients with other cardiovascular risk factors: the VAST study. Clin Ther. 2005;27(5):578-87.

29. Fuchs FD. The role of angiotensin receptor blockers in the prevention of cardiovascular and renal disease: time for reassessment? Evid Based Med. $2013 ; 18(2): 44-7$.

30. Lithell H, et al. The Study on Cognition and Prognosis in the Elderly (SCOPE): principal results of a randomized double-blind intervention trial. J Hypertens. 2003;21(5):875-86. 
31. Telmisartan Randomised AssessmeNt Study in A.C.E.i.s.w.c.D.I., et al. Effects of the angiotensin-receptor blocker telmisartan on cardiovascular events in high-risk patients intolerant to angiotensin-converting enzyme inhibitors: a randomised controlled trial. Lancet. 2008;372(9644):1174-83.

32. Yusuf S, et al. Telmisartan to prevent recurrent stroke and cardiovascular events. $\mathrm{N}$ Engl J Med. 2008;359(12):1225-37.

33. NS Group, et al. Effect of valsartan on the incidence of diabetes and cardiovascular events. N Engl J Med 2010. 362(16):1477-90.

34. Imai E, et al. Effects of olmesartan on renal and cardiovascular outcomes in type 2 diabetes with overt nephropathy: a multicentre, randomised, placebo-controlled study. Diabetologia. 2011;54(12):2978-86.

35. Mauer M, et al. Renal and retinal effects of enalapril and losartan in type 1 diabetes. $N$ Engl J Med. 2009;361(1):40-51.

36. Investigators $\mathrm{O}$, et al. Telmisartan, ramipril, or both in patients at high risk for vascular events. N Engl J Med. 2008;358(15):1547-59.

37. Fuchs FD, DiNicolantonio JJ. Angiotensin receptor blockers for prevention of cardiovascular disease: where does the evidence stand? Open Heart. 2015;2(1):e000236.

38. Bangalore $S$, et al. Angiotensin receptor blockers and risk of myocardial infarction: meta-analyses and trial sequential analyses of 147,020 patients from randomised trials. BMJ. 2011;342:d2234.

39. van Vark LC, et al. Angiotensin-converting enzyme inhibitors reduce mortality in hypertension: a meta-analysis of randomized clinical trials of renin-angiotensin-aldosterone system inhibitors involving 158,998 patients. Eur Heart J. 2012;33(16):2088-97.

40. Cheng J, et al. Effect of angiotensin-converting enzyme inhibitors and angiotensin II receptor blockers on all-cause mortality, cardiovascular deaths, and cardiovascular events in patients with diabetes mellitus: a meta-analysis. JAMA Intern Med. 2014;174(5):773-85.

41. Elgendy IY, et al. Efficacy and safety of angiotensin receptor blockers in older patients: a meta-analysis of randomized trials. Am J Hypertens. 2015;28(5):576-85.

42. Benicar HCT prescribing information. Revised 07/2013. Daiichi Sankyo, Inc. Reference ID: $3335147 . \quad$ http://www.accessdata.fda.gov/ drugsatfda_docs/label/2013/021532s022lbl.pdf. Accessed June 26, 2016.

43. Calhoun DA, et al. Triple antihypertensive therapy with amlodipine, valsartan, and hydrochlorothiazide: a randomized clinical trial. Hypertension. 2009;54(1):32-9.

44. Laeis P, Puchler K, Kirch W. The pharmacokinetic and metabolic profile of olmesartan medoxomil limits the risk of clinically relevant drug interaction. J Hypertens Suppl. 2001;19(1):S21-32.

45. Scott LJ, McCormack PL. Olmesartan medoxomil: a review of its use in the management of hypertension. Drugs. 2008;68(9):1239-72.

46. Ma SF, et al. Hydrolysis of angiotensin II receptor blocker prodrug olmesartan medoxomil by human serum albumin and identification of its catalytic active sites. Drug Metab Dispos. 2005;33(12):1911-9.

47. Daiichi Sankyo UK Limited. Olmetec plus film-coated tablets $20 \mathrm{mg} / 12.5 \mathrm{mg}$ and $20 \mathrm{mg} / 25 \mathrm{mg}$; summary of product characteristics. http://emc. medicines.org.uk; information for the user, http:// www.medicines.org.uk/emc/PIL.17689.latest.pdf. Accessed June 26, 2016.

48. Novartis. Diovan-HCT prescribing information. https://www.pharma.us.novartis.com/sites/www. pharma.us.novartis.com/files/diovan_hct.pdf. Accessed June 26, 2016.

49. Chrysant SG, Chavanu KJ, Xu J. Combination therapy with olmesartan medoxomil and hydrochlorothiazide: secondary analysis of the proportion of patients achieving recommended blood pressure goals from a randomized, double-blind, factorial study. Am J Cardiovasc Drugs. 2009;9(4):241-51.

50. Chrysant SG, et al. Evaluation of antihypertensive therapy with the combination of olmesartan medoxomil and hydrochlorothiazide. Am J Hypertens. 2004;17(3):252-9.

51. Kumbla DK, et al. WIN OVER study: efficacy and safety of olmesartan in Indian hypertensive patients: results of an open-label, non-comparative, multi-centric, post marketing observational study. Indian Heart J. 2014;66(3):340-4.

52. Bohm M, Ewald S, Olmebest Study A. Blood pressure reduction with olmesartan in mild-to-moderate essential hypertension: a planned interim analysis of an open-label sub-study in German patients. Curr Med Res Opin. 2006;22(7):1375-80.

53. Brunner HR, Stumpe KO, Januszewicz A. Antihypertensive efficacy of olmesartan medoxomil and 
candesartan cilexetil assessed by 24-hour ambulatory blood pressure monitoring in patients with essential hypertension. Clin Drug Investig. 2003;23(7):419-30.

54. Oparil S, et al. Comparative efficacy of olmesartan, losartan, valsartan, and irbesartan in the control of essential hypertension. J Clin Hypertens (Greenwich). 2001;3(5):283-91, 318.

55. Smith DH, Dubiel R, Jones M. Use of 24-hour ambulatory blood pressure monitoring to assess antihypertensive efficacy: a comparison of olmesartan medoxomil, losartan potassium, valsartan, and irbesartan. Am J Cardiovasc Drugs. 2005;5(1):41-50.

56. Chrysant SG, et al. Efficacy and safety of triple-combination therapy with olmesartan, amlodipine, and hydrochlorothiazide in study participants with hypertension and diabetes: a subpopulation analysis of the TRINITY study. J Am Soc Hypertens. 2012;6(2):132-41.

57. Chrysant SG, Marbury TC, Silfani TN. Use of 24-h ambulatory blood pressure monitoring to assess blood pressure control: a comparison of olmesartan medoxomil and amlodipine besylate. Blood Press Monit. 2006;11(3):135-41.

58. Omboni $\mathrm{S}$, et al. Antihypertensive efficacy and safety of olmesartan medoxomil and ramipril in elderly mild-to-moderate essential hypertensive patients with or without metabolic syndrome: a pooled post hoc analysis of two comparative trials. Drugs Aging. 2012;29(12):981-92.

59. Stumpe KO, Ludwig M. Antihypertensive efficacy of olmesartan compared with other antihypertensive drugs. J Hum Hypertens. 2002;16(Suppl 2):S24-8.

60. Wang L, et al. Antihypertensive effects of olmesartan compared with other angiotensin receptor blockers: a meta-analysis. Am J Cardiovasc Drugs. 2012;12(5):335-44.

61. Chrysant SG, et al. Efficacy and tolerability of amlodipine plus olmesartan medoxomil in patients with difficult-to-treat hypertension. J Hum Hypertens. 2010;24(11):730-8.

62. Chrysant SG, et al. The combination of olmesartan medoxomil and amlodipine besylate in controlling high blood pressure: $\mathrm{COACH}$, a randomized, double-blind, placebo-controlled, 8-week factorial efficacy and safety study. Clin Ther. 2008;30(4):587-604.

63. Derosa G, et al. Different aspects of sartan + calcium antagonist association compared to the single therapy on inflammation and metabolic parameters in hypertensive patients. Inflammation. 2014;37(1):154-62.

64. Derosa G, et al. Effects of an olmesartan/amlodipine fixed dose on blood pressure control, some adipocytokines and interleukins levels compared with olmesartan or amlodipine monotherapies. J Clin Pharm Ther. 2013;38(1):48-55.

65. Derosa G, et al. Olmesartan/amlodipine combination versus olmesartan or amlodipine monotherapies on blood pressure and insulin resistance in a sample of hypertensive patients. Clin Exp Hypertens. 2013;35(5):301-7.

66. Derosa G, et al. Results from a 12 months, randomized, clinical trial comparing an olmesartan/ amlodipine single pill combination to olmesartan and amlodipine monotherapies on blood pressure and inflammation. Eur J Pharm Sci. 2014;51:26-33.

67. Derosa G, et al. Variation of some inflammatory markers in hypertensive patients after 1 year of olmesartan/amlodipine single-pill combination compared with olmesartan or amlodipine monotherapies. J Am Soc Hypertens. 2013;7(1):32-9.

68. Sievers $P$, et al. Combined treatment with olmesartan medoxomil and amlodipine besylate attenuates atherosclerotic lesion progression in a model of advanced atherosclerosis. Drug Des Devel Ther. 2015;9:3935-42.

69. Agabiti-Rosei E, et al. Central blood pressure measurements and antihypertensive therapy: a consensus document. Hypertension. 2007;50(1):154-60.

70. Matsui Y, et al. Differential effects between a calcium channel blocker and a diuretic when used in combination with angiotensin II receptor blocker on central aortic pressure in hypertensive patients. Hypertension. 2009;54(4):716-23.

71. Daikuhara H, Kikuchi F, Ishida T. The combination of OLmesartan and a CAlcium channel blocker (azelnidipine) or candesartan and a calcium channel blocker (amlodipine) in type 2 diabetic hypertensive patients: the OLCA study. Diab Vasc Dis Res. 2012;9(4):280-6.

72. Axthelm C, et al. Efficacy and tolerability of the single-pill combination of aliskiren $300 \mathrm{mg} / \mathrm{am}$ lodipine $10 \mathrm{mg}$ in hypertensive patients not controlled by olmesartan $40 \mathrm{mg} /$ amlodipine $10 \mathrm{mg}$. Curr Med Res Opin. 2012;28(1):69-78.

73. Ruilope L, Schaefer A. The fixed-dose combination of olmesartan/amlodipine was superior in central aortic blood pressure reduction compared with perindopril/amlodipine: a randomized, 
double-blind trial in patients with hypertension. Adv Ther. 2013;30(12):1086-99.

74. Ruilope LM, Investigators SS. Fixed-combination olmesartan/amlodipine was superior to perindopril + amlodipine in reducing central systolic blood pressure in hypertensive patients with diabetes. J Clin Hypertens (Greenwich). 2016;18(6):528-35.

75. Oparil S, et al. Triple therapy with olmesartan medoxomil, amlodipine besylate, and hydrochlorothiazide in adult patients with hypertension: the TRINITY multicenter, randomized, double-blind, 12-week, parallel-group study. Clin Ther. 2010;32(7):1252-69.

76. Pickering TG, et al. When and how to use self (home) and ambulatory blood pressure monitoring. J Am Soc Hypertens. 2010;4(2):56-61.

77. Kereiakes DJ, et al. Olmesartan/amlodipine/hydrochlorothiazide in participants with hypertension and diabetes, chronic kidney disease, or chronic cardiovascular disease: a subanalysis of the multicenter, randomized, double-blind, parallel-group TRINITY study. Cardiovasc Diabetol. 2012;11:134.

78. Roth EM, et al. Olmesartan/amlodipine/hydrochlorothiazide in obese participants with hypertension: a TRINITY subanalysis. J Clin Hypertens (Greenwich). 2013;15(8):584-92.

79. Chrysant SG, et al. Triple-combination therapy with olmesartan, amlodipine, and hydrochlorothiazide in black and non-black study participants with hypertension: the TRINITY randomized, double-blind, 12-week, parallel-group study. Am J Cardiovasc Drugs. 2012;12(4):233-43.

80. Sakata Y, et al. Clinical impacts of additive use of olmesartan in hypertensive patients with chronic heart failure: the supplemental benefit of an angiotensin receptor blocker in hypertensive patients with stable heart failure using olmesartan (SUPPORT) trial. Eur Heart J. 2015;36(15):915-23.

81. Jung HW, et al. A multicenter, non-comparative study to evaluate the efficacy and safety of fixed-dose olmesartan/amlodipine in Korean patients with hypertension who are naive or non-responders to anti-hypertensive monotherapy (ACE-HY study). Clin Exp Hypertens. 2015;37(6):482-9.

82. Mohan JC, et al. Short term safety and tolerability of a fixed dose combination of olmesartan, amlodipine and hydrochlorothiazide. J Clin Diagn Res. 2015;9(8):OC10-3.

83. Neutel JM. Clinical studies of CS-866, the newest angiotensin II receptor antagonist. Am J Cardiol. 2001;87(8A):37C-43C.
84. Ball KJ, Williams PA, Stumpe KO. Relative efficacy of an angiotensin II antagonist compared with other antihypertensive agents. Olmesartan medoxomil versus antihypertensives. J Hypertens Suppl. 2001;19(1):S49-56.

85. Benicar HCT prescribing information. Revised 07/2013. Daiichi Sankyo, I.R.I.A.f.U.h.w.a.f.g.d.d.l.s.l.p. and A.S. 23.

86. Galanopoulos M, et al. Small bowel enteropathy associated with olmesartan medoxomil treatment. Ann Gastroenterol. 2017;30(1):131-3.

87. Uehara $\mathrm{T}$, et al. Olmesartan-induced enteropathy manifesting as Wernicke-Korsakoff syndrome. Intern Med. 2016;55(24):3675-8.

88. Kulai $\mathrm{T}$, et al. Duodenal villous atrophy in a TTG-negative patient taking olmesartan: a case report and review of the literature. Can J Gastroenterol Hepatol. 2016;2016:6091571.

89. Hammoudi N, et al. Olmesartan-induced enteropathy associated with cutaneous lesions. Clin Case Rep. 2016;4(4):379-82.

90. Desruisseaux C, et al. Adding water to the mill: olmesartan-induced collagenous sprue-a case report and brief literature review. Can J Gastroenterol Hepatol. 2016;2016:4837270.

91. Rubio-Tapia A, et al. Severe spruelike enteropathy associated with olmesartan. Mayo Clin Proc. 2012;87(8):732-8.

92. DeGaetani M, et al. Villous atrophy and negative celiac serology: a diagnostic and therapeutic dilemma. Am J Gastroenterol. 2013;108(5): 647-53.

93. Burbure $\mathrm{N}$, et al. Olmesartan-associated sprue-like enteropathy: a systematic review with emphasis on histopathology. Hum Pathol. 2016;50:127-34.

94. Marietta EV, et al. Immunopathogenesis of olmesartan-associated enteropathy. Aliment Pharmacol Ther. 2015;42(11-12):1303-14.

95. Ianiro G, et al. Systematic review: sprue-like enteropathy associated with olmesartan. Aliment Pharmacol Ther. 2014;40(1):16-23.

96. Rubio-Tapia A. Sprue-like enteropathy associated with olmesartan-broadening the differential diagnosis of enteropathy. Aliment Pharmacol Ther. 2014;40(11-12):1362-3.

97. Marthey L, et al. Olmesartan-associated enteropathy: results of a national survey. Aliment Pharmacol Ther. 2014;40(9):1103-9. 
98. FDA Drug Safety Communication. FDA approves label changes to include intestinal problems (sprue-like enteropathy) linked to blood pressure medicine. olmesartan medoxomil. http://www.fda. gov/downloads/Drugs/DrugSafety/UCM359496.pdf. Accessed Feb 6, 2017.

99. Thayer JF, Yamamoto SS, Brosschot JF. The relationship of autonomic imbalance, heart rate variability and cardiovascular disease risk factors. Int J Cardiol. 2010;141(2):122-31.

100. Saruta T, et al. Comparison of olmesartan combined with a calcium channel blocker or a diuretic in elderly hypertensive patients (COLM Study): safety and tolerability. Hypertens Res. 2015;38(2):132-6.

101. Al-Majed AR, et al. Losartan: comprehensive profile. Profiles Drug Subst Excip Relat Methodol. 2015;40:159-94.

102. Lacourciere Y, et al. Antihypertensive efficacy and tolerability of two fixed-dose combinations of valsartan and hydrochlorothiazide compared with valsartan monotherapy in patients with stage 2 or 3 systolic hypertension: an 8-week, randomized, double-blind, parallel-group trial. Clin Ther. 2005;27(7):1013-21.

103. Gleiter $\mathrm{CH}$, et al. Candesartan. Cardiovasc Drug Rev. 2004;22(4):263-84.

104. Brunner HR. The new angiotensin II receptor antagonist, irbesartan: pharmacokinetic and pharmacodynamic considerations. Am J Hypertens. 1997;10(12 Pt 2):311S-7S.

105. Neutel JM, et al. A comparison of the efficacy and safety of irbesartan/HCTZ combination therapy with irbesartan and HCTZ monotherapy in the treatment of moderate hypertension. J Hum Hypertens. 2008;22(4):266-74.
106. Bottorff MB, Tenero DM. Pharmacokinetics of eprosartan in healthy subjects, patients with hypertension, and special populations. Pharmacotherapy. 1999;19(4 Pt 2):73S-8S.

107. Gavras I, Gavras H. Safety and tolerability of eprosartan. Pharmacotherapy. 1999;19(4 Pt 2):102S-7S.

108. Chopra A. Molecular imaging and contrast agent database (MICAD), In: ${ }^{11} \mathrm{C}$-labeled telmisartan, an angiotensin II type 1 receptor antagonist. MD: National Center for Biotechnology Information, NLM, Bethesda; 2004.

109. Zheng Z, Lin S, Shi H. A systematic review and meta-analysis of telmisartan versus valsartan in the management of essential hypertension. J Clin Hypertens (Greenwich). 2010;12(6):414-21.

110. Gardner SF, Franks AM. Olmesartan medoxomil: the seventh angiotensin receptor antagonist. Ann Pharmacother. 2003;37(1):99-105.

111. Mire DE, Silfani TN, Pugsley MK. A review of the structural and functional features of olmesartan medoxomil, an angiotensin receptor blocker. J Cardiovasc Pharmacol. 2005;46(5):585-93.

112. Park JB, et al. Safety and efficacy of fimasartan in patients with arterial hypertension (Safe-KanArb study): an open-label observational study. Am J Cardiovasc Drugs. 2013;13(1):47-56.

113. Ghim JL, et al. Absolute bioavailability and pharmacokinetics of the angiotensin II receptor antagonist fimasartan in healthy subjects. J Clin Pharmacol. 2016;56(5):576-80.

114. Zaiken K, Cheng JW. Azilsartan medoxomil: a new angiotensin receptor blocker. Clin Ther. 2011;33(11):1577-89. 